\title{
LiVre-Arbítrio e a Relação Mente e CÉrebro EM BENJAMIM LIBET
}

\author{
Jonas GonçAlves Coelho
}

\begin{abstract}
My purpose is to reflect critically on how Benjamin Libet interprets his experiments, which are focused primarily on the question of free will. These experiments have often been considered as scientific evidence against free will, to the extent that they would have shown that the intention and will result from conscious brain processes, which are unconscious and precedents. But that is not the position of Libet, which distinguishes intention and conscious will, arguing that only the first results from previous and unconscious brain processes, while the second is autonomous and able to act causally on brain. Thus, Libet choose to ignore the suggestion of its initial experiments, that is, that all mental events result of specific brain processes. I argue that Libet ignores it because he is not able to understand how mental events, being essentially separated and at the same time the result of brain activity, could act causally on the brain.
\end{abstract}

Keywords: Free will; mind-brain; Libet.

\section{Introdução}

O meu objetivo no presente artigo é refletir criticamente sobre o modo como Benjamim Libet interpreta os experimentos por ele realizados, os quais têm como foco principal a questão do livre-arbítrio. Esses experimentos têm sido frequentemente considerados como uma prova científica contra o livre-arbítrio, na medida em que teriam mostrado que a intenção e a vontade conscientes resultam de processos cerebrais, os quais, por serem inconscientes e anteriores, não poderiam ser controlados por essa mesma vontade. Mas não é essa a posição de Libet, que distingue a intenção e a vontade consciente, postulando que apenas a primeira resulta de processos cerebrais anteriores e inconscientes, enquanto que a segunda é autônoma em relação ao cérebro, ao mesmo tempo em que pode agir causalmente sobre este. Desse modo, Libet prefere ignorar a sugestão inicial de seus experimentos, ou seja, a de que todo evento mental resulta ou é efeito de processos cerebrais específicos.

Procurarei mostrar, em concordância com alguns dos primeiros críticos de Libet, as razões que podem ser apresentadas para justificar a posição filosófica ambígua frente ao problema da relação mente-cérebro, ou seja, a de que existem alguns fenômenos mentais resultantes da atividade do cérebro e outros independentes do cérebro. Argumentarei que Libet prefere essa solução, cujas facetas procurarei apresentar, por não ser capaz de responder à seguinte difícil questão filosófica: sendo os

Principia 18(1): 153-174 (2014).

Published by NEL — Epistemology and Logic Research Group, Federal University of Santa Catarina (UFSC), Brazil. 
eventos mentais essencialmente distintos e, ao mesmo tempo, resultantes da atividade cerebral, poderiam eles agir causalmente sobre o cérebro? Para Libet, assim como para muitos outros pensadores, se não há algum tipo de poder causal e autonomia da mente em relação ao cérebro, não há espaço para o livre-arbítrio, e, se não há livre-arbítrio, não se pode atribuir responsabilidade moral.

Visando desenvolver esses aspectos do pensamento de Libet, apresentarei inicialmente uma de suas versões do experimento envolvendo o livre-arbítrio, junto com a sua defesa do livre-arbítrio, a seguir, o modo como Libet enfrenta o tema da relação mente-cérebro e, por fim, as dificuldades e limites da posição de Libet face ao problema da relação mente-cérebro. ${ }^{1}$

\section{Livre-arbítrio e Cérebro}

Grosso modo, os experimentos de Libet consistiam no monitoramento da atividade cerebral de sujeitos humanos, antes e durante a execução de ações simples, como a flexão dos dedos ou do pulso da mão direita, sempre que eles sentissem vontade, ou seja, a ação deveria ser voluntária e espontânea. Isso significa, primeiramente, que a ação deveria originar-se "endogenamente" e "não como resposta a um estímulo ou sugestão externos"; segundo, que não deveria haver "restrições ou compulsões impostas externamente, as quais, direta ou imediatamente controlassem a iniciação e performance do ato do sujeito"; por fim, e o "mais importante", que os sujeitos deveriam sentir "introspectivamente que eles estão realizando o ato por sua própria iniciativa e que eles são livres para começar ou não começar o ato que desejam [...]" (Libet 1985, p.529).

Para Libet, o fato de os sujeitos terem que seguir instruções do experimentador, tais como "realizar o ato motor prescrito em algum tempo após o início de cada experimento" e "prestar atenção introspectiva ao instante do início do impulso, desejo ou decisão de realizar cada um desses atos e à correlata posição espacial de um marcador girando sobre a face de um relógio (indicando o "tempo do relógio")" (Libet 1985, p.530), seria compatível com a orientação de que cada um dos atos prescritos deve iniciar-se "espontaneamente", sem um planejamento deliberado ou atenção prévia ao "panorama da ação". Enfim, as ações de flexionar rapidamente os dedos ou o pulso seriam preestabelecidas, mas o momento de seu início deveria ser escolhido pelo sujeito do experimento, o qual poderia, inclusive, "não expressar em ações qualquer dado impulso ou decisão inicial de agir [...]" (Libet 1985, p.530). Os sujeitos teriam concordado e seguido rigorosamente essas instruções.

Os sujeitos, na verdade, relataram que a inclinação para cada ato apareceu espontaneamente ("do nada"), que eles estavam conscientes de seu impulso ou decisão de agir antes de cada ato, que eles se sentiram no controle consci-

Principia 18(1): 153-174 (2014). 
ente para agir ou não agir e que eles não sentiram nenhuma pressão externa ou psicológica que afetasse o momento em que decidiram agir. Desse modo, a despeito dos requisitos experimentais, as condições básicas estabelecidas acima para um ato voluntário foram satisfeitas. (Libet 1985, p.530)

Libet considerava fundamental que a decisão sobre o início da ação fosse espontânea para que ele pudesse identificar os processos cerebrais envolvidos nas ações "sem confundi-los com características deliberativas ou preparatórias que não resultam necessariamente em ação" (Libet 1985, p.530). A importância da escolha do momento de agir, nas situações em que a ação realmente ocorre, para a identificação da atividade cerebral aí envolvida, é reafirmada e justificada detalhadamente por Libet nos seguintes termos:

A liberdade do sujeito de agir em qualquer tempo de sua escolha realmente fornece o elemento crucial desse estudo. O objetivo era, de fato, comparar o tempo do início da intenção consciente de agir e o tempo do início do processo cerebral associado. A escolha específica de que ato realizar não era material para a questão a ser perguntada.

Os processos volitivos podem operar em vários níveis de organização e tempo relativos ao ato voluntário. Esses podem incluir a deliberação consciente da escolha de alternativas, assim como o que fazer e quando, se agir ou não agir, se concordar ou não com ordens ou instruções externas para agir, e assim por diante. Se quaisquer desses processos resultam na performance motora de um ato voluntário, eles devem de algum modo trabalhar para o "caminho da ativação motora comum final" no cérebro. Sem uma performance motora aberta, qualquer deliberação volitiva, escolha ou planejamento pode ser interessante por seu conteúdo psicológico ou mental, mas não constitui uma ação voluntária. É especificamente essa performance aberta do ato que foi experimentalmente estudada por nós. (Libet 1985, p.530)

Tendo apresentado, em linhas gerais, os requisitos e objetivos do experimento de Libet, entre os quais destaco a espontaneidade na escolha do início da ação e a identificação dos processos cerebrais envolvidos, passo à descrição dos resultados e de suas implicações. Segundo Libet, a eletromiografia dos sujeitos do experimento mostrou a ocorrência de mudanças elétricas na atividade do cérebro, "potenciais de prontidão", em média 550ms antes da "ativação do músculo envolvido" na ação proposta e, o mais sugestivo, 350ms antes do aparecimento do "desejo ou intenção consciente" de agir, momento que foi apontado pelos próprios sujeitos a partir da lembrança da posição do ponteiro de um relógio. Eis um dos relatos do experimento:

Os atos voluntários são precedidos por "potenciais de prontidão" (RPs) eletrofisiológicos. Com os atos espontâneos, destituídos de qualquer pré-planejamento, a principal mudança negativa de RP começa em torno de $-550 \mathrm{~ms}$.

Principia 18(1): 153-174 (2014). 
Esses RPs foram utilizados para indicar o tempo de início mínimo da atividade cerebral que precede um ato voluntário completamente endógeno. $\mathrm{O}$ tempo da intenção consciente de agir foi obtido a partir da lembrança que os sujeitos tinham da posição espacial do marcador giratório de um relógio, no tempo de sua consciência inicial da intenção ou querer mover (W). W ocorreu em torno de $-200 \mathrm{~ms}$. Experimentos controlados, nos quais o estímulo na pele foi cronometrado (S), ajudaram a avaliar cada erro do sujeito no relato do tempo do relógio para a consciência de qualquer evento percebido. (Libet 1985, p.529)

Se considerarmos procedente e precisa a descrição que Libet apresenta do experimento por ele realizado, o resultado mais relevante consiste, sem dúvida, na demonstração de que o "ato voluntariamente livre" começa no cérebro "bem antes de a pessoa saber que ela quer agir" (Libet 1999, p.5), contrariando, desse modo, a concepção tradicional e dominante segundo a qual a vontade consciente precede ou inicia o acontecimento cerebral fazendo com que o cérebro execute o "ato pretendido". Em outras palavras, o experimento de Libet pretende mostrar que o ato voluntário começa inconscientemente no cérebro, como se o cérebro decidisse o curso da ação antes e, portanto, independentemente da vontade consciente do agente.

O início dos RPs começa regularmente pelo menos várias centenas de ms antes do tempo relatado para a consciência de qualquer intenção de agir, no caso dos atos realizados espontaneamente. Parece, consequentemente, que alguma atividade neuronal associada com a eventual performance do ato começou bem antes que qualquer (evocável) intenção ou intervenção consciente fosse possível. Isso leva à conclusão de que a iniciação cerebral, mesmo de um ato voluntário espontâneo, pode e usualmente começa inconscientemente. (O termo "inconsciente" refere-se aqui simplesmente a todos os processos que não são expressos como uma experiência consciente; isso pode incluir e não distingue entre pré-consciente, subconsciente ou outros possíveis processos inconscientes não relatáveis). Colocado de outro modo, o cérebro "decide" iniciar ou, pelo menos, preparar para iniciar o ato antes que haja qualquer consciência subjetiva relatável de que essa decisão tenha sido tomada. (Libet 1985, p. 536)

Libet não vê problema algum com essa tese, na medida em que defende que a intenção consciente, assim como outras formas de experiência consciente, é propriedade do cérebro ou, como ele mesmo diz, o ato voluntário consciente começa inconscientemente no cérebro porque a intenção consciente de agir resulta da atividade cerebral que a precede, desde que esta dure um tempo mínimo, ou seja, a atividade cerebral específica deve durar um tempo suficiente para que a experiência consciente aconteça.

esses achados estão de acordo com uma prévia hipótese geral que tratou com a questão de como a experiência consciente subjetiva de cada indiví-

Principia 18(1): 153-174 (2014). 
duo está relacionada aos processos cerebrais e que distingue isso a partir de processos inconscientes. Aquela hipótese propunha que algum substancial período de tempo de atividade cerebral apropriada durando centenas de ms poderia ser requerida para induzir muitas formas de experiências conscientes específicas. A hipótese desenvolveu-se fora dos achados experimentais de que atividades corticais devem persistir por aproximadamente 500ms ou mais antes que a "adequação neuronal" para uma experiência sensorial consciente seja concluída. Isso conduziu à inferência posterior, sustentada pela evidência, de que aquelas atividades cerebrais, que não persistem o tempo suficiente permanecem em níveis inconscientes. A presente evidência sugere que um período substancial similar de atividade cerebral pode também ser requerido para concluir a "adequação neuronal" para uma experiência de intenção ou desejo consciente realizar um ato voluntário. A experiência da intenção consciente de agir, nesses termos, originar-se-ia como um resultado secundário do anterior processo iniciado inconsciente; no entanto, ela poderia ainda ter um papel ou em completar o processo iniciado ("disparador consciente") ou em bloquear sua progressão ("veto"). (Libet 1985, p.536)

Contra uma interpretação apressada segundo a qual o experimento apresentado demonstra que a intenção consciente, enquanto resultante de atividade cerebral específica anterior, não têm por si mesma um efetivo poder causal sobre a ação, Libet adverte, como vemos no final da citação anterior, que a "experiência da intenção consciente" tem um papel na realização ou impedimento da ação. Mas, como esclarece em outros textos, não é a intenção e sim a vontade consciente que, pelo fato de preceder a ativação do músculo relacionado à ação em cerca de $150 \mathrm{~ms}$, seria capaz "de parar ou vetar o progresso final do processo volitivo, de modo que nenhuma ação muscular aconteça de fato" (Libet 1999, p.51). Desse modo, a vontade consciente tem um poder causal sobre a atividade cerebral, por meio da qual interfere ativamente sobre o destino da ação. Logo, não devemos concluir que a atividade cerebral inconsciente, responsável pela intenção de agir, seja também, por si mesma, a causa da própria ação, pois, para Libet, o fato de a vontade consciente anteceder ao ato propriamente dito, dá àquela, como já o dissemos, um poder causal, ou de consumar a ação iniciada, ou de detê-la.

Se a vontade consciente tem um papel privilegiado na determinação da ação, a precedência da atividade cerebral inconsciente em relação à intenção de agir não implica a negação do livre-arbítrio. Apenas deveríamos deslocar o foco, ou seja, o livre-arbítrio não está na possibilidade de interferir nos acontecimentos cerebrais inconscientes que precedem a ação, portanto, não está na capacidade de "iniciar um ato voluntário", mas sim no poder de controlar a realização ou não do ato. Em outras palavras, a vontade consciente selecionaria quais das "iniciativas inconscientes das ações voluntárias ‘borbulhando’ no cérebro [...] podem chegar a uma ação ou quais 
vetar ou abortar" (Libet 1999, p.54) ou, como conclui Libet em um dos primeiros relatos de seu experimento:

O papel da vontade consciente não seria iniciar um ato voluntário específico, mas antes selecionar e controlar o resultado volitivo. Propõe-se que a vontade consciente pode funcionar de modo a permitir ou evitar a implementação motora da intenção de agir que se origina inconscientemente. Alternativamente, pode ser o necessário para uma consciente ativação ou disparo, sem o qual o resultado motor final não seguiria os processos cerebrais inconscientes iniciadores e preparatórios [...] Os achados experimentais nos levam a concluir que os atos voluntários podem ser iniciados por processos cerebrais inconscientes antes que a intenção consciente apareça, mas que o controle consciente sobre a performance motora atual dos atos permanece possível [...] Eu proponho a tese de que o controle volitivo consciente pode operar não para iniciar o processo volitivo, mas para o selecionar e controlar, ou permitindo, ou disparando o resultado motor final do processo iniciado inconscientemente, ou vetando a progressão da ativação motora atual. (Libet 1985, p.529)

A defesa da compatibilidade entre livre-arbítrio e início cerebral e inconsciente da intenção de agir é reiterada por Libet em outro momento do texto no qual, utilizando-se do mesmo argumento, procura preservar o espaço para a responsabilidade moral, com a qual, como veremos ainda nesta seção, o autor parece estar especialmente preocupado.

[...] é importante enfatizar que os presentes achados experimentais não excluem o potencial para os "filosoficamente real" livre-arbítrio e responsabilidade individual. Embora o processo volitivo possa ser iniciado por atividades cerebrais inconscientes, o controle consciente da performance motora real dos atos voluntários definitivamente permanece possível. Os achados deveriam, consequentemente, serem tomados não como antagonistas ao livrearbítrio, mas antes como afetando a visão de como o livre-arbítrio poderia operar. Processos associados com responsabilidade individual e livre-arbítrio "operariam" não para iniciar um ato voluntário, mas para selecionar e controlar os resultados volitivos. (Libet 1985, p.538)

Daí Libet criticar os sistemas religiosos que transformam quase todos os indivíduos em pecadores ao condená-los por seus impulsos, desejos ou intenções pecaminosas, os quais não poderiam ser controlados conscientemente, visto que, como revelam as suas pesquisas, esses desejos e intenções iniciam-se e desenvolvem-se inconscientemente no cérebro. Considerando-se que apenas as ações poderiam ser controladas conscientemente, apenas elas poderiam ser julgadas moralmente. Nesse sentido, os sistemas ético-legais estariam mais de acordo com a realidade dos fatos do que as religiões, visto que aqueles privilegiariam, em seus julgamentos, as ações

Principia 18(1): 153-174 (2014). 
ao invés dos desejos ou intenções: "Desde que é o desempenho de um ato que conscientemente pode ser controlado, deve ser legítimo prender indivíduos culpados e responsáveis por seus atos" (Libet 1999, p.49). Nessa passagem de 1999, Libet reafirma a mesma postura crítica, já adotada no texto de 1985 como veremos na citação abaixo, em relação às doutrinas religiosas, quando elas pretendem responsabilizar moralmente alguém não apenas por suas ações, sobre as quais tem controle por serem precedidas por decisões conscientes, mas, também, por sua intenção de agir, ou seja, para Libet, os agentes não poderiam ser responsabilizados por algo que acontece anteriormente e inconscientemente em seus cérebros, e que está, por isso, fora de seu controle consciente.

O conceito de veto ou bloqueio consciente da performance motora de intenções específicas de agir está em geral de acordo com certas visões religiosas e humanísticas do comportamento ético e responsabilidade individual. $\mathrm{O}$ "autocontrole" do agir independente das intenções de alguém é comumente advogado; nos termos presentes ele operaria pela seleção ou controle consciente da implementação ou não do processo volitivo final iniciado inconscientemente. Muitas restrições éticas, tais como a maioria dos Dez Mandamentos, são injunções para não agir de determinado modo. Por outro lado, se a intenção final de agir origina-se inconscientemente, a mera aparição de uma intenção não poderia ser conscientemente evitada, ainda que sua consumação em ação motora pudesse ser controlada conscientemente. Não seria surpresa, consequentemente, se os sistemas filosóficos ou religiosos criassem insuperáveis dificuldades morais e psicológicas quando eles castigam indivíduos por simplesmente terem uma intenção ou impulso mental de fazer alguma coisa inaceitável, ainda quando isso não é efetivado. (Libet 1985, p.539)

Libet deixa claro que a preocupação pragmática é um dos fatores motivadores de sua defesa do livre-arbítrio ao dizer que não se poderia responsabilizar moralmente e criminalmente uma pessoa normal se não houvesse livre-arbítrio, o qual dependeria de um controle consciente da ação, e que este não seria possível sem um controle consciente direto "sobre a natureza de quaisquer processos inconscientes precedentes” (Libet 1999, p.48). Para Libet, a dependência da mente em relação ao cérebro inviabilizaria o livre-arbítrio e, consequentemente, a responsabilidade moral e criminal das pessoas normais as quais deveriam então receber o mesmo tratamento dado a alguns casos patológicos nos quais se pode ver claramente que o indivíduo não tem controle sobre os fatores desencadeantes de suas ações.

Nós não prendemos as pessoas responsáveis por ações representadas inconscientemente, sem a possibilidade de controle consciente. Por exemplo, ações de uma pessoa durante uma confiscação psicomotora epilética, ou com síndrome de Tourette, etc., não são consideradas como ações de livre-arbítrio.

Principia 18(1): 153-174 (2014). 
Por que então deveria um ato inconscientemente desenvolvido por um indivíduo normal, um processo sobre o qual ele também não tem nenhum controle consciente, ser considerado um ato de livre-arbítrio? (Libet 1999, p.48)

Sabedor de que essa argumentação pragmática por si só não prova a existência do livre-arbítrio, Libet procura reforçá-la apresentando o que considera como uma forte evidência a favor do livre-arbítrio, a questionável evidência fenomenológica:

nós devemos reconhecer que a experiência quase universal, de que nós podemos agir com liberdade e escolha independente, fornece uma espécie de evidência à primeira vista que processos mentais conscientes podem causalmente controlar alguns processos cerebrais [...] O fato fenomenal é que a maioria de nós sentimos que temos de fato livre-arbítrio, ao menos para algumas de nossas ações e dentro de certos limites que podem ser impostos por nosso estado cerebral e por nosso ambiente. Os sentimentos intuitivos sobre o fenômeno de livre-arbítrio formam uma base fundamental para pareceres de nossa natureza humana, e muito cuidado deve ser tomado para não acreditar em conclusões supostamente científicas sobre eles que realmente residem sobre suposições ad hocs. Uma teoria que simplesmente interpreta o fenômeno de livre-arbítrio como ilusório e nega a validez deste fato fenomenal é menos atraente que uma teoria que aceita ou acomoda o fato fenomenal. (Libet 1999, p.50)

Por fim, alegando que o ônus da prova deve recair sobre os defensores do determinismo, e que não há ainda evidência científica definitiva a favor do determinismo ou do livre-arbítrio, Libet defende que deveríamos optar pela defesa do livre-arbítrio, pois essa tese estaria mais de acordo com o nosso "sentimento profundo", como defendido na citação anterior.

Numa questão tão fundamentalmente importante, a nossa visão de quem nós somos, uma alegação para a natureza ilusória deve ser baseada em evidência claramente direta. Tal evidência não está disponível; nem deterministas propõem sequer um potencial projeto experimental para testar a teoria [...] Minha conclusão sobre livre-arbítrio, algo genuinamente livre no sentido de não-determinado, é então que sua existência é ao menos tão boa, senão a melhor opção científica que a sua negação pela teoria determinista. Dada a natureza especulativa de ambas as teorias deterministas e não-deterministas, por que não adotar a visão que nós temos livre-arbítrio (até que alguma evidência contrária real possa aparecer, se isso ocorrer). Tal visão iria ao menos permitir-nos prosseguir de certa maneira que aceita e acomoda o próprio sentimento profundo que nós temos livre-arbítrio. Nós não necessitaríamos ver-nos como máquinas que agem numa maneira completamente controlada pelas leis físicas conhecidas. (Libet 1999, p. 56)

Principia 18(1): 153-174 (2014). 
O coroamento da retórica de Libet a favor do livre-arbítrio acontece com a seguinte citação do novelista Isaac Bashevis Singer: "O maior presente que a humanidade recebeu é o livre-arbítrio. É verdadeiro que somos limitados em nosso livrearbítrio. Mas o pouco livre-arbítrio que nós temos é um presente tão grande e é potencialmente tão valoroso que por si mesmo a vida fica valorosa" (Libet 1999, p.56).

Após breve descrição do experimento de Libet e apresentação de sua problemática interpretação, a qual lhe permite defender o livre-arbítrio, passarei a considerar a metafísica que a sustenta, ou seja, o modo como Libet caracteriza a mente e pensa a relação entre esta e o cérebro.

\section{Relação Mente e Cérebro}

Ao apresentar os primeiros resultados de seus experimentos envolvendo a questão do livre-arbítrio, Libet tinha consciência de estar lidando com uma das questões centrais da filosofia, ou seja, a relação mente-cérebro, a partir de um de seus "mistérios", isto é, o modo como "um ato voluntário origina-se em relação aos processos cerebrais que o medeiam" (Libet 1985, p.529), questão que se insere no contexto mais amplo de como os processos mentais conscientes relacionam-se com a atividade cerebral. Segundo a descrição de Libet, o ato voluntário é precedido pela vontade consciente de efetivar ou vetar a intenção, a qual, por sua vez, é precedida pela intenção de agir, sendo esta resultante de específicos eventos cerebrais inconscientes. A questão é se a vontade consciente também resulta de processos cerebrais inconscientes e, em que medida isso implicaria em ela ter ou não um poder causal sobre a ação.

Libet considera que a precedência da atividade cerebral em relação à intenção consciente de agir não inviabiliza o poder causal da vontade consciente, a qual é caracterizada como "a ativa intervenção consciente para afetar ou controlar um resultado cerebral [...]" (Libet 1985, p.36). Defende que se poderia tratar das "potencialidades" ou "possibilidades operacionais para o controle consciente", apenas no "nível fenomenológico", ou seja, "no nível que não requer um compromisso com quaisquer alternativas filosóficas específicas para a interação mente-cérebro, quer essas sejam determinismo versus livre-arbítrio ou epifenomenismo versus intervenção mental" (Libet 1985, p.536). Isso porque entende que a afirmação do poder causal da vontade consciente controladora é compatível com as principais concepções filosóficas sobre a relação mente-cérebro, seja algum tipo de fisicalismo emergentista, que o autor chama de monismo, seja alguma forma de dualismo interacionista.

Para que o controle dos processos volitivos seja exercido como uma iniciativa consciente, parece na verdade necessário postular que as funções de controle consciente podem surgir sem iniciação anterior por processos cerebrais

Principia 18(1): 153-174 (2014). 
inconscientes, num contexto no qual a consciência consciente da intenção de agir já se tenha desenvolvido. Esse postulado pode estar de acordo, ou com uma visão monista, segundo a qual uma função de controle consciente poderia ser uma contínua característica de uma já emergente consciência consciente, ou com uma visão interacionista dualista. (Libet 1985, p.538)

Diferentemente da intenção consciente de agir, ou do "tornar-se consciente do desejo de agir", não haveria nenhuma "evidência experimental" que "requeira que uma atividade neural específica preceda e determine a natureza da função de controle consciente" (Libet 1999, p.52). Existiria, assim, uma "consciência total", a qual envolveria tanto o "conteúdo do desejo consciente" de agir quanto "o conteúdo dos fatores que podem afetar um veto consciente" e, embora essa consciência total possa exigir ou ser precedida por processos cerebrais, a "decisão real de vetar", ou seja, o "conteúdo daquela consciência" não exigira processos cerebrais antecedentes que a suportem.

\begin{abstract}
Não está excluída a possibilidade de que os fatores sobre os quais a decisão de vetar (controle) está baseada se desenvolvam por processos inconscientes que precedem o veto. No entanto, a decisão consciente de vetar ainda poderia ser feita sem a especificação direta para essa decisão pelos processos inconscientes precedentes. Isto é, poder-se-ia conscientemente aceitar ou rejeitar o programa oferecido acima pela formação inteira de processos cerebrais precedentes. A consciência da decisão de vetar poderia ser pensada exigir processos inconscientes precedentes, mas o conteúdo daquela consciência (a decisão real de vetar) é uma característica separada que não necessita ter o mesmo requisito. (Libet 1999, p.49)
\end{abstract}

Mas por que Libet pensa que "a consciência da decisão de vetar" pode exigir processos cerebrais antecedentes enquanto que o seu conteúdo, definido como a "decisão real de vetar", é uma "característica separada que não necessita ter o mesmo requisito"? Vejamos se Libet fornece uma solução para essa questão em seus textos mais recentes. Começarei pelo artigo de 2003, Can Conscious Experience Affect Brain Activity?, cujo título sugere que Libet pretende responder a questão de se a experiência consciente pode afetar a atividade do cérebro. Nesse texto, plenamente consciente das dificuldades relacionadas à relação mente-cérebro envolvidas na interpretação de seus experimentos, e apresentando essas dificuldades a partir das críticas de Velmans, Libet começa por resumir os resultados de suas pesquisas experimentais de 1983, as quais teriam mostrado que o processo volitivo consciente, ou "desejo consciente de agir", seria iniciado antes da ação em 350ms no cérebro cuja atividade elétrica — potencial de prontidão — teria sido identificada experimentalmente, embora permanecesse inconsciente para o sujeito do experimento: "de fato, os sujeitos não têm relatável consciência ou sentimento intuitivo de que o cérebro 
iniciou um processo antes de aparecer seu desejo/impulso consciente para agir" (Libet 2003, p.24).

Embora a precedência da atividade cerebral em relação à intenção ou vontade consciente de agir indique que aquela seja um acontecimento involuntário, ou seja, não determinado pela "vontade livre consciente", isso não implicaria a ausência de livre-arbítrio, visto que, como já tivemos a oportunidade de ver anteriormente, os experimentos teriam também mostrado que a vontade consciente precede o processo motor final em aproximadamente $200 \mathrm{~ms}$, o que significa que a vontade consciente tem o controle da ação - "resultado do processo volitivo" - , ainda que não tenha o controle do processo cerebral que a inicia. Para Libet, o poder de veto é um dado fenomenológico inquestionável, ou seja, todos nós experimentamos muitas vezes o "desejo ou impulso de realizar uma ação e de ter vetado a sua real implementação", por exemplo, quando esse impulso é inaceitável socialmente, ou é incompatível com a nossa personalidade.

A partir daí vemos Libet, citando Velmans, reapresentar a dificuldade "óbvia"de seu posicionamento em relação à questão da relação mente-cérebro: "Por que a decisão de veto não tem os seus próprios antecedentes inconscientes, exatamente como parece ser o caso da própria vontade consciente?" (Libet 2003, p.25) Se fosse o caso, continua a crítica, a decisão de veto também não seria resultante de uma vontade livre consciente. $\mathrm{O}$ primeiro passo de Libet para responder a essa objeção consiste na retomada de um argumento já apresentado anteriormente (Libet 1999), o qual estabelece que o "veto consciente", por ser uma "função de controle", e não apenas um "tornar-se consciente do desejo de agir", "não precisa ser decidido por processos inconscientes precedentes". Parece que o ponto central desse argumento é que a função de controle implica a possibilidade de "um conteúdo consciente de fatores que podem afetar a decisão de veto consciente" (Libet 2003, p.25), ou seja, o poder de veto dependeria do conteúdo da vontade consciente, o que significa que não é necessária a especificação de processos cerebrais inconscientes e anteriores para explicar a decisão de vetar. Libet parece defender que o que é fundamental para a decisão de vetar é o conjunto de conteúdos conscientes envolvidos na decisão, e é isso que garantiria alguma liberdade e autonomia da vontade consciente em relação aos processos cerebrais:

"Essa visão do veto permite que uma genuína vontade consciente livre seja
um agente controlador na performance de um ato voluntário, ainda que a
vontade livre consciente pareça não iniciar o processo volitivo [...] concluo
que o veto consciente é um fenômeno que fornece uma oportunidade para
o livre-arbítrio agir como um agente controlador em uma ação voluntária"
(Libet 2003, p.25).

Mas como essa visão do veto em termos de seu conteúdo ajudaria a explicar a ação causal da vontade consciente sobre o cérebro e, consequentemente, sobre a 
ação? Essa questão nos leva de volta ao modo como Libet trata da relação mentecérebro no texto citado, o que nos leva a afirmação de uma ontologia dualista que, como veremos, não ajuda a resolver o problema. O seu primeiro passo para o estabelecimento de uma concepção dualista consiste na distinção mente-cérebro e na afirmação da irredutibilidade da primeira ao segundo. A distinção dos fenômenos mentais ancora-se, inicialmente, numa perspectiva epistemológica, ou seja, retomando a clássica argumentação cartesiana, Libet argumenta que os fenômenos mentais conscientes não são um dado objetivo que poderia ser observado no cérebro - visão de terceira pessoa - , mas um dado introspectivo apreendido apenas subjetivamente visão de primeira pessoa: "A experiência subjetiva é acessível apenas para o indivíduo que a tem (a tão chamada visão de primeira pessoa)" (Libet 2003, p.26 ).

O segundo passo na defesa de uma concepção dualista, segundo a qual o mental não tem propriedades físicas (se o tivesse poderia ser observado pela inspeção do cérebro; não seria um dado exclusivamente introspectivo), consiste em argumentar que, embora os eventos mentais possam "ser correlacionados experimentalmente com atividades neurais específicas do cérebro", não se pode generalizar essa tese, como o fazem os fisicalistas, os quais acreditam que todos os processos mentais poderão ser correlacionados com processos cerebrais. Segundo Libet, essa correlação nunca poderá ser estabelecida, e não devido a limitações ao conhecimento impostas pela natureza do que é pesquisado e pelos limites tecnológicos, mas sim porque essa correlação nem sempre existe: "Há alguma evidência de que uma correlação total pode nunca ocorrer; isto é, pode haver eventos mentais conscientes que parecem ocorrer não ligados ou baseados em eventos neurais" (Libet 2003, p.26).

Mas como isso seria possível? Libet não concorda com o que seria uma versão da teoria da identidade, de acordo com a qual "há um único substrato (para o cérebro, no caso) o qual exibe uma 'qualidade interna' (acessível apenas ao indivíduo) e uma 'qualidade externa' (observável fisicamente por um observador interno)" (Libet 2003, p.26). Por não explicitar o que é o 'substrato' e como ambas as qualidades seriam por ele exibidas, ficaria sem solução a questão da "natureza única da relação 'mente-cérebro' na qual uma característica é a experiência subjetiva consciente que não pode ser observada por meios físicos externos" (Libet 2003, p.26).

Como solucionar o problema? Libet retoma uma hipótese por ele apresentada em 1994 e 1999, cuja principal noção é a que ele chama de "campo mental consciente" (CMC), o qual emergiria de "funções cerebrais apropriadas". O campo mental consciente unificaria a experiência consciente "baseada em um imenso número de diferentes eventos neurais" e seria capaz de "afetar certas atividades neurais que forneceriam uma avenida para a ação da vontade consciente no cérebro" (Libet 2003, p.27). O CMC seria um novo campo 'natural', um campo não físico, no sentido de que ele não poderia ser diretamente observado ou medido por nenhum meio físico externo. Esse atributo seria a característica bem conhecida da experiência subjetiva 
consciente, a qual seria acessível apenas ao indivíduo que a vivencia. Libet acredita que a sua teoria do CMC preservaria as propriedades específicas da experiência consciente, incluindo o livre-arbítrio, e esclarece que não está defendendo algum tipo de dualismo cartesiano, visto que o "CMC não existe sem o cérebro vivo, e é uma propriedade emergente daquele cérebro" (Libet 2003, p.27). No que consiste efetivamente essa noção de "campo mental consciente" e como ela poderia contribuir para a solução da questão da relação mente e cérebro? Essas questões são tratadas de forma mais detalhada no texto Reflections on the Interaction of the Mind and Brain, de 2006.

Nesse texto, Libet começa por reafirmar a concepção dualista segundo a qual mente e cérebro são "entidades fenomenológicas" distintas. Isso parece significar que a distinção ontológica está baseada numa distinção epistemológica, ou seja, na medida em que a experiência subjetiva consciente "é acessível apenas ao sujeito que a tem" e só pode "ser estudada por relatos dados pelo próprio sujeito", não podendo, portanto, "ser observada ou estudada por observadores externos com qualquer tipo de aparelho físico", Libet infere que a "a experiência subjetiva (a mente consciente) é um fenômeno não-físico” (Libet 2006, p.322). Daí decorre inevitavelmente o problema da relação entre o físico e o mental, de como "as moléculas e estruturas dos materialistas originam a experiência subjetiva", o que não seria solucionado pela redução do mental ao físico, igualando o primeiro a alguma configuração de atividades neurais: "Simplesmente afirmar que alguma (desconhecida) configuração de atividades neuronais iguala-se à consciência (experiência subjetiva) evita ou desvia do problema" (Libet 2006, p.323).

Qual seria então a solução? A proposta apresentada por Libet, que ele anteriormente chama de "Campo Mental Consciente" e agora chama de "Campo Mental Cerebral" (CMF), consiste na mesma tese de que a experiência subjetiva consciente "envolve uma propriedade integrativa" (Libet 2006, p.323). A ideia é que a experiência consciente é unificada ainda que ela resulte de bilhões de células neurais em ação em diferentes partes do cérebro, como é o caso, por exemplo, da experiência visual de um objeto como uma "suave estrutura organizada" resultante da ação de várias áreas distintas do cérebro responsáveis pelas "cores, configurações espaciais, movimentos e significado (interpretação)" (Libet 2006, p.323). Para testar essa correlação, ou seja, a sua teoria do CMF, Libet cita o teste por ele proposto bem antes (já apresentados em artigos de 1993 e 1994):

Uma pequena placa do córtex sensorial (servindo a qualquer modalidade) é neuronalmente isolada, mas mantida viável por fazer todos os cortes corticais sob a pia-máter. Isso permite aos vasos sanguíneos na pia projetar na placa isolada e fornecer fluxo sanguíneo dos ramos arteriais que mergulham verticalmente no córtex. A predição é que a estimulação elétrica da placa sensorial produzirá uma resposta subjetiva relatável pelo sujeito. Isto

Principia 18(1): 153-174 (2014). 
é, a atividade na placa isolada pode contribuir para produzir a sua própria porção do CMF. (Libet 2006, p.324)

Libet defende novamente uma posição dualista não-cartesiana ao considerar que o Campo Mental Cerebral não é um "fantasma na máquina”, ou seja, por um lado, ele não é "separável do cérebro", visto ser uma propriedade produzida pela atividade de bilhões de neurônios sem as quais não poderia existir e, por outro lado, essas propriedades não seriam redutíveis à atividade cerebral, pois não seriam "diretamente previsíveis" a partir da atividade daqueles neurônios, sendo um "fenômeno não-físico, como a experiência subjetiva que ele representa" (Libet 2006, p.324). Libet considera que, por não ser possível descrever o "processo pelo qual o CMF origina-se de seus elementos contribuintes", o CMF deveria "ser visto como um novo 'dado' fenômeno fundamental da natureza, o qual é diferente de outros 'dados' fundamentais, tais como a gravidade ou o eletromagnetismo” (Libet 2006, p.324).

A defesa de um tipo de dualismo de propriedade é ainda motivada pelos experimentos, também citados por Libet desde as primeiras de suas pesquisas sobre livre-arbítrio, segundo os quais a experiência consciente, por exemplo, a consciência sensorial, aparece um tempo após os acontecimentos cerebrais específicos, ainda que o sujeito não perceba esses atrasos: "De algum modo, o tempo subjetivo da consciência atrasada aparece sem atraso. É como se a consciência atrasada fosse subjetivamente referida retroativamente no tempo ao tempo da resposta evocada primária do córtex sensorial.” (Libet 2006, p.324) Libet retoma a tese já defendida anteriormente, segundo a qual as experiências subjetivas conscientes surgem de processos cerebrais inconscientes quando estes têm uma duração mínima.

Consciência mental pode ser atrasada acima de $0,5 \mathrm{~s}$. Consequentemente, processos que são inconscientes, isto é, sem consciência, devem precedê-los. Se alguém extrapola essa situação para todos os eventos mentais (reconhecidamente sem evidência direta), então todos os eventos mentais são iniciados e desenvolvidos inconscientemente. Na verdade, a maioria dos eventos mentais são provavelmente completamente inconscientes. A principal diferença entre eventos inconscientes e conscientes poderia ser a duração do processo que os origina. Se a duração é muito curta, o evento permanece inconsciente; ele apenas atinge o nível de consciência se a duração é suficientemente longa. Essa distinção baseada na duração dos processos tem sido denominada teoria "on-time". (Libet 2006, p.324)

As propriedades dessa teoria do campo mental consciente foram resumidas por Libet em uma carta ao editor do Journal of Theoretical Biology, 1996, intitulada Conscious Mind as a Field, apresentando-a em oposição à concepção de Popper tal como elaborada por Lindahl \& Arhem. Referindo-se aos próprios textos Neurophysiology of Consciousness, de 1993 e A testable field theory of mind-brain interaction, de 1994, Libet defende que as propriedades do "campo mental consciente" seriam a 
seguintes: primeiro, ele "emergiria como uma função de atividades neurais apropriadas no cérebro; segundo, ele teria o atributo da experiência subjetiva consciente"; terceiro, "ele poderia agir de volta sobre certas atividades neurais e consequentemente afetar o resultado comportamental, como na ação querida"; ele "seria responsável pela unidade da experiência subjetiva ainda que a última emerja de uma miríade de atividades de bilhões de células nervosas e suas interações sinápticas e não-sinápticas"; ele, como as experiências subjetivas constituídas nele, seria acessível apenas para o indivíduo que tem as experiências, ele não poderia ser diretamente observado por nenhum equipamento físico externo, a não ser indiretamente, por efeitos que ele introduza sobre resultados comportamentais (exatamente como a vontade consciente evidenciou)" (1996, p.223).

Considero que o que foi apresentado até o momento é, senão tudo, pelo menos o mais importante do que Libet tem a dizer a respeito da relação mente-cérebro e, consequentemente, em prol da autonomia e poder causal da vontade consciente, enfim, a favor do livre-arbítrio. Apresentarei, a seguir, o que considero serem as principais dificuldades desse empreendimento de Libet.

\section{Críticas ao Dualismo de Libet}

Penso que a principal dificuldade, já anteriormente apontada e reconhecida pelo próprio Libet, é o fato de o processo consciente espontâneo, "simplesmente tornar-se consciente do desejo de agir", resultar da atividade cerebral, e o processo consciente voluntário, "a função de controle consciente", independer do cérebro. Parece razoável supor que, se uma atividade mental consciente depende de acontecimentos cerebrais, que a mesma relação de dependência aplica-se a todos os outros eventos mentais conscientes, ainda que não haja evidência experimental contra a possibilidade de o processo consciente voluntário independer da atividade cerebral. Nesses termos, Libet parece assumir uma posição ambígua face à relação mente-cérebro, ou seja, o autor defende ora que a mente depende do cérebro, ora que dele independe.

Essa dificuldade, ao lado de várias outras, foi apontada logo após a publicação das primeiras pesquisas de Libet sobre o livre-arbítrio, em especial, em um texto de 1985, o qual reúne, além do artigo de Libet Unconscious cerebral initiative and the role of conscious will in voluntary action, um conjunto de considerações críticas de estudiosos de diversas áreas do conhecimento e, na última parte, as respostas de Libet aos seus críticos. Apresento, a seguir, as críticas dirigidas ao modo como Libet defende o livre-arbítrio, em especial, a sua posição face à questão mente-cérebro.

Um dos críticos de Libet é Bruno Breitmeyer, que no texto Problems with the psychophysics of intention, diz que Libet apenas circunda, sem enfrentar efetivamente, a importante questão do papel causal da consciência. Breitmeyer questiona a proposta 
de Libet, já apresentada no final da primeira seção deste artigo, de que se discuta "as possibilidades operacionais do controle consciente da ação em bases puramente fenomenológicas, sem comprometimento com alternativas filosóficas específicas, tais como determinismo versus livre-arbítrio ou epifenomenalismo versus intervenção mental" (Breitmeyer 1985, p.540). Segundo Breitmeyer, esse "parêntese fenomenológico" seria impossível, pois isso significaria ignorar as próprias "hipóteses metafísicas ocultas por trás do empreendimento científico por ele [Libet] empreendido" (Breitmeyer 1985, p.540). Para o autor, não se pode falar sobre controle consciente sem que se assuma uma posição em relação ao debate entre epifenomenalismo e intervenção mental consciente, afinal, o próprio Libet defenderia que a consciência "disparadora" ou "vetante" da ação, "é precedida por atividades neurais causalmente eficazes, ainda que inconscientes, exatamente como no caso da intenção consciente de mover", o que significa que "aquela consciência é meramente um pensamento posterior, uma reflexão sobre eventos fora de seu controle causal e, consequentemente, epifenomenal" (Breitmeyer 1985, p.540). Breitmeyer considera, por fim, e nesse caso não muito apropriadamente, que Libet ignora a importância causal da consciência, algo inconcebível para quem partilha a tese da evolução natural.

Para ter evoluído, ela [a consciência] deve ser tão causalmente eficaz como é a mão daquele que escreve estas palavras. Consequentemente, a consciência, incluindo qualquer consciência "disparadora" ou de "veto", clama por alguma forma de intervenção mental. Como cientistas, nós não podemos ficar à margem e suspender ou colocar entre parênteses a tese da evolução natural. Fazer isso seria mais mistificar a consciência em um grau garantidor de silêncio. (Breitmeyer 1985, p.540)

A crítica de Arthur Danto, no texto intitulado Conciousness and motor control, difere apenas em relação a este último aspecto, concordando plenamente com o primeiro. O problema para Danto não é que Libet "ignora a importância causal da consciência", mas sim que ele a apresenta ora como dependente do cérebro ora como se dele independesse. Refere-se duramente a Libet como um "fisiologista que, em virtude de seu preconceito metafísico, necessita de ajuda filosófica" (Danto 1985, p.541). O preconceito metafísico seria a única justificativa para que Libet considere necessário postular, no final do artigo, algo incompatível "com tudo o que até aquele ponto ele tinha sofrido para mostrar", ou seja, contra o que sugeria inicialmente. Defende que existem "funções de controle consciente" as quais independeriam de "processos cerebrais inconscientes": "no último fatídico intervalo, abruptamente e sem motivação experimental, entre a intenção e o ato cai a sombra de ideias alienígenas. Essas são a "função de controle consciente" que "dispara" ou "veta" o ato e que salta, não convocada cerebralmente, ao ser [...]" (Danto 1985, p.541).

Assumindo uma posição filosófica face à questão da natureza da mente e da causação mental, Danto considera que uma "função de controle consciente" só pode 
ter efeito fisiológico se ela mesma "tem alguma substância fisiológica". Assim, do mesmo modo que a intenção ou querer agir experienciados subjetivamente são precedidos por processos cerebrais neuronais passíveis de serem identificados experimentalmente, deveria ser também uma "questão empírica", se as "funções de controle consciente" são iniciadas cerebralmente. Libet ignoraria as implicações de seus próprios achados experimentais em favor de uma metafisica que considera indispensável à defesa do livre-arbítrio e da responsabilidade moral.

Então, por que deveria parecer necessário postulá-las como não precedidas a menos que se acredite que a atividade inconsciente precedente deve arruinar alguma teoria querida pelo escritor - talvez a posição sobre a questão do livre-arbítrio? Se Libet está certo que "os presentes achados experimentais não excluem o potencial para a 'filosoficamente real' responsabilidade individual e livre-arbítrio", por que ele deveria agir como se eles o excluíssem ao postular o que ele sente que deve estar no lugar para que a responsabilidade e a liberdade tenham aplicação? A filosofia deve aprender a viver com a verdade científica [...] (Danto 1985, p.541).

Uma crítica mais detalhada ao ambivalente posicionamento de Libet face à questão da relação mente-cérebro é apresentada por R.J. Nelson, no texto Libet's Dualism. Nelson concorda com dois aspectos das interpretações de Libet, ou seja, com as teses de que o "processo cerebral inconsciente sinalizado pelos RPs" inicia o impulso consciente e que a ação pode ser controlada pela vontade consciente. A questão é "se algum processo cerebral mediador precede a ocorrência do controle consciente" (Nelson 1985, p.550). Em relação a esse ponto, Nelson também considera que a posição de Libet é ambígua. Primeiro porque não haveria, segundo Libet, uma "técnica disponível para gravar e analisar RPs que possam estar associados" a vetos conscientes; o que não significa, diz Nelson, que não haja processos cerebrais subjacentes a essa vontade consciente de vetar. Libet ignoraria essa advertência ao postular que o controle voluntário consciente independe do cérebro, o que não é sustentado pelo experimento.

Ainda segundo Nelson, Libet poderia ter feito algo melhor, ou seja, ter "suspendido o julgamento" até que pesquisas posteriores permitissem um posicionamento bem fundamentado a respeito da dependência ou não da vontade consciente de veto em relação a processos cerebrais, visto que o sentir que a vontade consciente é livre não se constituiria por si só como uma garantia da autonomia da função de controle consciente em relação à atividade cerebral. Para Nelson, o fato de Libet defender que um evento mental, a intenção consciente de agir, é iniciada inconscientemente no cérebro, enquanto que outro evento mental, a função de controle consciente, independe da atividade cerebral, revela um "tipo estranho de dualismo" em relação à questão mente e cérebro, na verdade um "ininteligível" e "inacreditável" duplo dualismo, um dualismo interativo e outro não interativo, ininteligível: 
O duplo dualismo é este: (1) algum evento mental, isto é, impulsos, são causados por eventos físicos. Essa é uma forma de interacionismo (não de um substantivo interacionismo, visto que nenhuma reivindicação de que há uma mente substancial sendo influenciada por um cérebro material); por outro lado, (2) outros eventos mentais, isto é, o controle ativo consciente, poderia ser característica de uma consciência consciente emergente "já desenvolvida". (Como alternativa Libet sugere que o postulado "pode estar de acordo com uma visão interacionista dualista". Mas essa ideia é ininteligível. Se o controle é incausado por processos cerebrais inconscientes, ele certamente não pode ser o resultado de interação com o cérebro, a menos que a interação seja alguma coisa de que o sujeito é consciente ou, de outro modo, que haja algum tipo de processo corporal extracerebral que o causa - ambos extremamente improváveis.) Assim, o controle voluntário consciente é parte de um fluxo consciente paralelo, mas não interagindo com o processo cerebral. (Nelson 1985, p.550)

Nelson entende que essa posição ambígua de Libet explicar-se-ia no final de seu artigo, no qual deixa entrever uma preocupação em garantir "cientificamente", ou seja, tirando proveito da falta de evidência para a presença de fatores cerebrais na origem do controle voluntário consciente, "a proposição de que os seres humanos têm controle voluntário sobre pelo menos algumas de suas ações, no simples sentido da ética e psicologia popular" (Nelson 1985, p.550), ou seja, defender as nossas "intuições ordinárias", aquelas de nossos "momentos não-filosóficos" quando "a maioria de nós sente que as ações conscientes não são meramente parte e uma parcela de um fluxo puramente físico de eventos cerebrais" (Nelson 1985, p.550).

Às críticas apresentadas, acrescento algumas considerações sobre a teoria do "Campo Mental Cerebral" ou "Campo Mental Consciente" — "CMC", a qual, supostamente, contribuiria para resolver a ambiguidade de Libet em face da questão da relação mente-cérebro. Penso que essa teoria não contribui para a solução do problema mente-cérebro. Na verdade, até complica, visto que Libet reafirma a posição dualista de irredutibilidade da experiência subjetiva consciente aos processos cerebrais ao mesmo tempo em que postula que essas experiências resultam da atividade do cérebro, o que poderia ser generalizado para qualquer evento mental e confirmado por experimentos: "características do CMC podem ser correlacionadas com eventos cerebrais, ainda que o CMC seja não-físico, pelo estudo de relatos subjetivos dos sujeitos humanos" (Libet 2006, p.322).

O próprio Libet reconhece não apenas a dificuldade do problema, ao dizer que a "natureza da interação entre mente e cérebro é claramente difícil de entender, desde que ela envolve a produção de experiências subjetivas não-físicas por atividades neuronais apropriadas" (Libet 2006, p.325), mas também admite que a sua hipótese do "campo mental consciente" não consegue lidar com os "mais intratáveis mistérios" de "como a experiência subjetiva e o campo consciente proposto originam-se das 
atividades neurais" e de "como uma força mental consciente poderia agir de volta sobre o cérebro físico para influenciar os resultados neurais, como na ação querida" (Libet 1996, p.224). Há “o problema de relacionar a entidade campo mental ao enormemente complexo arranjo de atividades em bilhões de células nervosas" e, nesse sentido, o "importante desafio científico seria produzir evidência experimental para a proposta de interação em via dupla entre um campo consciente e um cérebro físico, sem tentar responder por que e como essas interações existem" (Libet 1996, p.224). Ou seja, no final, Libet propõe testar algo que não é objeto de muita controvérsia, pois, no final das contas, até mesmo Descartes aceitava a existência de uma interação mente e cérebro.

\section{Considerações Finais}

Posições como a de Libet, que, a partir das considerações epistemológicas citadas, defende que os eventos mentais não são físicos e, ao mesmo tempo, que eles resultam da atividade cerebral, tornam problemática a ideia de uma causação mental, ou seja, não explicam como a mente, sendo propriedade do cérebro, essencialmente distinta deste, poderia ser causa de algumas de suas atividades. Argumentei, neste artigo, que Libet não apresenta uma solução satisfatória para o problema, ora defendendo posições contraditórias acerca da relação mente-cérebro, ora reconhecendo a dificuldade de se entender essa relação. Parece que a sua motivação principal para a defesa da irredutibilidade e autonomia não claramente explicada do mental em relação ao cerebral decorre de sua compreensão de que pelo menos esse último aspecto é imprescindível para a defesa do livre-arbítrio e, consequentemente, da responsabilidade moral.

Embora Libet não ofereça uma solução satisfatória para o problema da causação mental, considero que ele aponta caminhos, já trilhados e promissores, para o enfrentamento dessa questão, admitindo-se a distinção e irredutibilidade do mental ao físico. Trata-se das ideias de que o cérebro é a causa da consciência, mas não de seu conteúdo, e de que a consciência tem uma "função de controle", as quais não serão aqui desenvolvidas tendo em vista os limites e objetivos deste artigo. A primeira nos remete às concepções externalistas da mente, segundo as quais a mente não pode ser reduzida ao cérebro, pelo fato de seus conteúdos, os pensamentos, serem produzidos ou individuados pelo ambiente físico e, especialmente, cultural, no qual a linguagem tem um papel fundamental. Se os pensamentos não são idênticos aos processos cerebrais, se eles dependem de algo externo ao cérebro, se a ação depende da atividade cerebral e, por fim, se pensamento afeta a ação pelo seu conteúdo, então seria legítimo postular algum tipo de causação não-cerebral.

Passo agora à outra ideia sugestiva de Libet, a da consciência como função de

Principia 18(1): 153-174 (2014). 
controle. Tratarei dela também brevemente a partir da seguinte citação do livro "E o cérebro criou o homem", do neurologista Antonio Damasio.

O mais curioso nos aspectos superiores da consciência é a notável ausência de um maestro antes de a execução ter início, embora surja um regente conforme a execução acontece. Para todos os efeitos, o maestro passa então a reger a orquestra, ainda que a execução tenha criado o maestro - o self —, e não o contrário. O maestro é gerado pela junção de sentimentos a um mecanismo de narrativa cerebral, embora nem por isso o maestro seja menos real. O maestro inegavelmente existe em nossa mente, e nada ganharíamos se o descartássemos como uma ilusão. (Damasio 2009, p.40)

Penso que a noção de consciência - propriedade essencial dos eventos mentais — entendida como uma "função de controle", no caso de Libet, ou "regente" no caso de Damasio, tenha o mérito de nos afastar da tão problemática ideia de causação mental. A consciência pode ser pensada como uma propriedade criada pelo cérebro, a qual em suas formas mais primitivas - percepção — permitiria uma relação com o mundo externo a partir inicialmente da recepção de estímulos físicos que implicariam a modificação adaptativa o próprio cérebro, além da modificação construída geneticamente. Já em suas formas mais complexas - culminando em níveis sofisticados de autoconsciência - a consciência regularia ou controlaria/regeria, parte da atividade cerebral, não apenas a partir da recepção diferenciada dos estímulos físicos, mas também da recepção de "estímulos" culturais, ou seja, ideias provenientes do mundo externo as quais modificariam o cérebro estruturalmente e funcionalmente.

Esse papel regulador/controlador/regente da consciência criaria um espaço para o livre-arbítrio, mas talvez um espaço restrito se considerarmos que, primeiro, a consciência não controla toda a atividade cerebral. O que significa que alterações estruturais e funcionais dependentes de fatores genéticos e ambientais podem interferir profundamente nas funções mente e ação, como mostrado amplamente pela literatura neurocientífica sobre doenças genéticas, lesões cerebrais e uso de substâncias químicas. Nesse sentido, o regente da orquestra não teria poder absoluto sobre as alterações individuais dos músicos e instrumentos da orquestra as quais poderiam comprometer o resultado final. Essas alterações individuais poderiam também ser provocadas por fatores anteriores e exteriores à orquestra, ou seja, as nossas decisões também resultariam do contexto cultural no qual estamos inseridos.

\section{Referências}

Bode, S.; He A. H.; Soon C. S. 2011. Tracking the unconscious generation of free decisions using ultra-high field fMRI. PLoS ONE 6(6): e21612.

Principia 18(1): 153-174 (2014). 
Breitmeyer, B. 1985. Problems with the psychophysics of intention. The behavioral and brain sciences 8: p.529-66.

Chun, S.S.; Brass, M.; Heinze, J.; Haynes, J. 2008. Unconscious determinants of free decisions in the human brain. Nature Neuroscience 11: April.

Damasio, A. 2009. E o cérebro criou o homem. São Paulo: Companhia das Letras.

Danto, A. 1985. Consciousness and motor control. The behavioral and brain sciences 8: 52966.

Haynes, J.; Rees, G. 2006. Decoding mental states from brain activity in humans. Nature Reviews/Neuroscience 7: July.

Libet, B. 1985. Unconscious cerebral initiative and the role of conscious will in voluntary action. The behavioral and brain sciences 8: p.529-66.

—. 1996 Consciouss Mind as a Field. Journal of Theoretical Biology 178: 223-24.

_. 1999 [2011]. Do we have free will? W. Sinnott-Armstrong; L. Nadel (ed.) Conscious will and responsibility. New York: Oxford University Press, 2011.

-2006. Reflections on the interaction of the mind and brain. Progress in Neurobiology 7: 322-26.

Nelson, R. J. 1985. Libet's dualism. The behavioral and brain sciences 8: 529-66.

Jonas GonçaLVES CoelHo

Universidade Estadual Paulista - UNESP

jonas@faac. unesp.br

Resumo. O meu objetivo é refletir criticamente sobre o modo como Benjamim Libet interpreta os experimentos por ele realizados, os quais têm como foco principal a questão do livre-arbítrio. Esses experimentos têm sido frequentemente considerados como uma prova científica contra o livre-arbítrio, na medida em que teriam mostrado que a intenção e a vontade conscientes resultam de processos cerebrais, os quais, por serem inconscientes e anteriores, não poderiam ser controlados por essa mesma vontade. Mas não é essa a posição de Libet, que distingue a intenção e a vontade consciente, postulando que apenas a primeira resulta de processos cerebrais anteriores e inconscientes, enquanto que a segunda é autônoma em relação ao cérebro, ao mesmo tempo em que pode agir causalmente sobre este. Desse modo, Libet prefere ignorar a sugestão inicial de seus experimentos, ou seja, a de que todo evento mental resulta ou é efeito de processos cerebrais específicos. Argumento que Libet a ignora por não ser capaz de entender a partir dela como os eventos mentais, sendo resultantes da atividade cerebral, poderiam agir causalmente sobre o cérebro.

Palavras-chave: Livre-arbítrio; mente-cérebro; Libet.

\section{Notas}

${ }^{1}$ São muitas as críticas feitas a Libet, várias delas envolvendo outros aspectos de seus experimentos, tais como a precisão, a generalização de seus resultados, o modo como usa os termos filosóficos etc. Tendo em vista que o objetivo principal deste artigo é tratar do posicionamento ambíguo de Libet face à questão da relação mente-cérebro, assumirei que seus experimentos, assim como outros experimentos contemporâneos envolvendo técnicas

Principia 18(1): 153-174 (2014). 
de imageamento do cérebro (cf. textos de Chun Siong Soon, John-Dylan Haynes e Stefan Bode, citados nas referências bibliográficas), teriam realmente mostrado que acontecimentos cerebrais específicos precedem eventos mentais específicos, sendo possível estabelecer a correlação entre eles.

Principia 18(1): 153-174 (2014). 